\section{"Eu sofri a dor inominável da injustiça": emoções, política e testemunho no discurso de Dilma Rousseff}

["I suffered the unnameable pain of injustice": emotions, politics and testimony in Dilma Rousseff's speech]

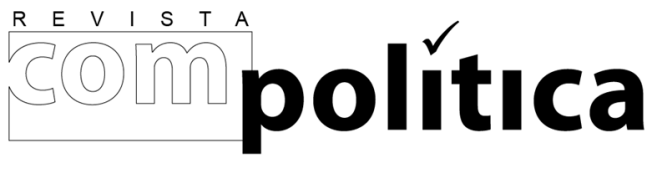

revista compolítica

2017, vol. 7(2)

compolitica.org/revista

ISSN: 2236-4781

DOI: 10.21878/compolitica.2017.7.2.304 () Open Access Journal

\author{
Amanda Medeiros \\ Universidade Federal do Rio de Janeiro \\ [Federal University of Rio de Janeiro]
}

\author{
Tatiane Leal \\ Universidade Federal do Rio de Janeiro \\ [Federal University of Rio de Janeiro]
}

\title{
Resumo
}

Este artigo analisa de que forma o lugar de vítima assumido por Dilma Rousseff no contexto do impeachment dialoga com entendimentos contemporâneos sobre o sofrimento, a compaixão e a política. Integram o corpus de análise o comunicado oficial de afastamento proferido pela presidenta dentro do Palácio do Planalto e o discurso feito, logo após, para os manifestantes que a apoiavam. A discussão realiza-se em torno de dois eixos: o lugar de vítima assumido pela presidenta e a dor enquanto emoção compartilhada e motor de compaixão. Para tanto, nos baseamos em autores do campo das teorias do trauma e da crítica social do sofrimento. Como metodologia, utilizamos a análise de discurso baseada em Foucault, a partir do conceito de raridade discursiva. Concluímos que o discurso da presidenta atua como instrumento terapêutico e motor de compaixão em um contexto em que o sofrimento emerge como experiência capaz de estabelecer identidades partilhadas, motivando novas formas de fazer política.

Palavras-chave: Dilma Rousseff, Impeachment, Vítima, Testemunho, Compaixão.

\begin{abstract}
This paper analyzes how the place of victim assumed by Dilma Rousseff in the context of impeachment dialogues with contemporary understandings about suffering, compassion and politics. The corpus of analysis includes the official statement issued by the president inside the Palácio do Planalto and the speach made to the demonstrators who supported her. The discussion presentes in two axes: the place of the victim assumed by the president, and the pain as a shared emotion and motor of compassion. For this, we rely on authors from trauma theories and social criticism of suffering. As a methodology, we use discourse analysis based on Foucault, based on the concept of discursive rarity. We conclude that the president's discourse acts as a therapeutic instrument and engine of compassion in a context where suffering emerges as an experience capable of establishing shared identities, motivating new ways of doing politics.
\end{abstract}

Keywords: Dilma Rousseff, Impeachment, Victim, Testimony, Compassion. 


\section{"Eu sofri a dor inominável da injustiça”: emoções, política e testemunho no discurso de Dilma Rousseff}

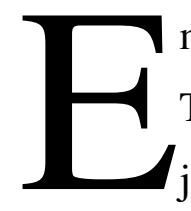
m 12 de maio de 2016, após decisão do Senado, Dilma Rousseff (Partido dos Trabalhadores - PT) foi afastada da presidência do Brasil para aguardar o julgamento de seu processo de impeachment. Em seu pronunciamento de despedida, antes de deixar o Palácio do Planalto, ela afirmou sua inocência diante dos crimes pelos quais era acusada. O discurso, no entanto, não se restringiu ao contexto político atual. Dilma se declarou vítima não apenas da "farsa jurídica e política" que teria orquestrado o processo de impeachment, mas de situações que teriam deixado marcas de sofrimento em sua história pessoal: a tortura infligida durante a ditadura militar, o câncer que a atingiu pouco antes de sua candidatura ao primeiro mandato e, agora, a violência simbólica da injustiça.

Os três eventos de naturezas aparentemente diferentes teriam em comum o efeito que Dilma compartilhava, através das câmeras, com seus eleitores: o sofrimento. Mesmo acometida pela dor - nas palavras da presidenta, "indizível, aflitiva e inominável” - ela tinha sido capaz de vencer desafios intransponíveis e emergiria, assim, como uma sobrevivente. A temática do sofrimento não foi a única a ser abordada por Dilma, que se preocupou em destrinchar e refutar as acusações feitas contra ela e em reafirmar o compromisso com os eleitores e com a democracia. Entretanto, a temática do sofrimento foi o recorte escolhido para estampar as manchetes de alguns dos principais veículos de comunicação do país. Portais de notícias on-line como o Terra ${ }^{1}$ e o $U o l^{2}$, revistas como a

\footnotetext{
${ }^{1}$ https://noticias.terra.com.br/brasil/politica/impeachment/estou-vivendo-a-dor-da-traicao-e-da-injustica-dizdilma,2e95b1b4817fbd35a109eeca84b14555mvsb2v98.html. Acesso em: 02 ago. 2016. ${ }^{2}$ http://noticias.uol.com.br/politica/ultimas-noticias/2016/05/12/pronunciamento-de-dilma-rousseff.htm. Acesso em: 02 ago. 2016.
} 
${\text { Carta } \text { Capital }^{3} \text { e a Exame }}^{4}$, jornais como o El País ${ }^{5}$ e $O G l o b o^{6}$, deram enfoque às emoções de Dilma e ao seu testemunho sobre a dor.

Mesmo marcado por um contexto político específico, o discurso de Dilma não é um fato isolado, mas dialoga com um fenômeno cultural marcante nas conformações subjetivas contemporâneas: a emergência da vítima como uma categoria identitária relevante. A partir da multiplicação da ideia de trauma como um termo guarda-chuva para abrigar eventos capazes de fazer irromper o sofrimento em meio ao curso das vidas comuns, o lugar de vítima se tornou passível de adesão por parte de múltiplos indivíduos em suas reivindicações, tanto pessoais, quanto coletivas: dos que sofreram bullying aos que viveram o abuso infantil, dos veteranos de guerra ao movimento feminista, o trauma passa a oferecer a possibilidade de uma identidade partilhada que uniria os mais diferentes indivíduos e grupos em uma comunidade de sofredores, em que o ideal de subjetividade passa a ser o do sobrevivente.

Este artigo tem como objetivo entender de que forma o lugar de vítima assumido por Dilma Rousseff dialoga com entendimentos contemporâneos sobre o sofrimento, a compaixão e a política. Uma breve contextualização do momento político que deu origem a esse discurso antecede a investigação empreendida. Como referencial teórico, temos como base autores do campo das teorias do trauma e da crítica social do sofrimento (Fassin \& Rechtman, 2009; Hacking, 1995; Vaz et. al., 2014). Integram o corpus de análise o comunicado oficial de afastamento proferido ainda dentro do Palácio do Planalto e o discurso feito pela presidenta do lado de fora do palácio, ao dirigir-se aos manifestantes que a apoiavam. Utilizando como metodologia a análise de discurso, assistimos aos vídeos das duas exposições, que foram disponibilizados na íntegra no YouTube e veiculados por portais de

\footnotetext{
${ }^{3}$ A edição 909 da revista trouxe na capa uma foto de Dilma Rousseff acompanhada justamente desse trecho de seu discurso: "Já sofri a dor indizível da tortura; já passei pela dor aflitiva da doença e hoje sofro a dor igualmente inominável da injustiça”. Disponível em: http://www.cartacapital.com.br/revista/909. Acesso em: 02 ago. 2016.

4 http://exame.abril.com.br/brasil/noticias/sofro-a-dor-da-injustica-mas-nao-esmoreco-diz-dilma. Acesso em: 02 ago. 2016.

${ }^{5}$ http://internacional.elpais.com/internacional/2016/05/12/actualidad/1463058824_745080.html. Acesso em: 02 ago. 2016.

${ }^{6} \mathrm{O}$ sofrimento de Dilma foi destaque em um dos blogs do jornal: http://blogs.oglobo.globo.com/agora-nobrasil/post/ja-vivi-dor-indizivel-da-tortura-da-doenca-e-agora-sofro-dor-inominavel-da-injustica.html.

Acesso em: 02 ago. 2016.
} 
notícias $^{7}$, e dividimos seu conteúdo em duas categorias, a partir das temáticas que se mostraram mais relevantes para a discussão: o lugar de vítima assumido por Dilma e a dor enquanto emoção compartilhada e motor de compaixão.

O conceito de discurso aqui é entendido a partir das concepções de Michel Foucault (1984; 2009; 2011). Investigar as narrativas midiáticas a partir de Foucault significa abandonar a dicotomia entre o real e sua representação na linguagem. Para o filósofo francês, o enunciado é também um acontecimento, na medida em que ele irrompe, não por acaso, em um certo tempo e em determinado espaço. Isso se traduz no conceito de raridade discursiva (Foucault, 2009). Como afirma Vaz e Rony (2011, p. 214),

\footnotetext{
Diante de um enunciado, a questão decisiva a ser colocada não é a de saber o que 'realmente' queria dizer apesar do que disse ou se representava adequadamente a realidade; a questão é, sim, por que precisamente esse enunciado, aqui e agora, e não outros que seriam ou já foram possíveis (Vaz \& Rony, 2011, p. 214).
}

Buscamos, assim, compreender de que forma o testemunho pessoal de sofrimento de Dilma Rousseff ilustra verdades do nosso tempo acerca das relações entre sofrimento, compaixão e política.

\section{O processo do impeachment de Dilma Rousseff}

Desde as eleições de 2014, quando Dilma Rousseff, candidata pelo Partido dos Trabalhadores (PT), foi reconduzida ao cargo de presidenta do Brasil com 51,64\% dos votos válidos, o cenário político e econômico do país mergulhou num processo crítico de intensas transformações ${ }^{8}$. Insatisfeito, o povo foi às ruas reivindicar mudanças, fossem elas

\footnotetext{
${ }^{7}$ O pronunciamento feito dentro do palácio está disponível em: https://www.youtube.com/watch?v=dnjJayjdAVU e o de fora do palácio em: http://g1.globo.com/politica/videos/v/dilma-faz-discurso-do-lado-de-fora-do-palacio-doplanalto/5018783/. O discurso oficial também teve sua transcrição divulgada na mídia, como pode ser visto em: http://oglobo.globo.com/brasil/confira-integra-do-discurso-de-despedida-de-dilma-19291552. Acesso em: 02 ago. 2016. ${ }^{8}$ Não objetivamos aqui ir além de uma breve apresentação do contexto do impeachment, tampouco entrar no mérito de apontar causas deste acontecimento, ou mesmo discutir estratégias políticas lançadas pelos sujeitos envolvidos.
} 
diretamente ligadas ou não à ideia de descontinuidade deste governo por meio do processo de impeachment.

Diante deste cenário, em 2 de dezembro de 2015, o presidente da Câmara dos Deputados, Eduardo Cunha - filiado ao Partido do Movimento Democrático Brasileiro (PMDB) -, acatou denúncia sobre possíveis crimes de responsabilidade cometidos pela presidenta, os quais versam sobre o desrespeito à Lei Orçamentária e à Lei de Improbidade Administrativa. Com a abertura do processo, as manifestações populares pró e contra impeachment espalharam-se por todo o país.

Como rito da questão processual, a princípio formou-se uma comissão especial na Câmara dos Deputados com a finalidade de discutir sobre a aceitação da abertura do impeachment. O relatório apresentado pela comissão especial, favorável ao impedimento da presidenta, seguiu para apreciação por parte do plenário da Câmara dos Deputados, e em 17 de abril de 2016, após mais de 40 horas de uma sessão extraordinária, foram contabilizados 367 votos favoráveis e 137 contrários à abertura do processo. Seguindo o rito, o parecer da Câmara foi enviado ao Senado, onde também, por meio de uma comissão especial, deu-se a aprovação do relatório. Foi então em 12 de maio que, mediante votação no Senado, o afastamento da presidenta Dilma foi confirmado por 55 dos 77 senadores presentes na sessão.

Definido o seu afastamento da Presidência da República pelo prazo máximo de 180 dias, Dilma Rousseff deixou o Palácio do Planalto em 12 de maio, quando, interinamente, o vice Michel Temer (PMDB) assumiu o cargo. Na ocasião, a presidenta afastada deu uma declaração à imprensa nas instalações internas do Palácio e, ao sair acompanhada de alguns membros de sua equipe técnica, falou ao povo que estava ali para apoiá-la. Em seus discursos, Dilma imprimiu um tom de denúncia, colocando-se, pois, em uma posição de vítima ao afirmar que o que estava em curso era um golpe político.

Perícia feita por comissão do impeachment concluiu que não houve crime de pedaladas fiscais nas ações de Dilma, todavia, a questão processual não foi interrompida e, com 61 votos favoráveis e 20 contrários, o Senado decidiu pela destituição da presidenta em 31 de 
agosto de 2016. Com a finalização do processo, o cargo passou a ser ocupado pelo até então vice-presidente Michel Temer.

\section{A construção discursiva de uma sobrevivente}

O discurso de Dilma Rousseff à imprensa tinha uma motivação primordial: expor a posição do Governo Federal em relação à decisão do Senado de afastá-la por 180 dias em decorrência da instauração formal do processo de impeachment. Como os comunicados oficiais anteriores, desde o aceite da denúncia pelo legislativo, tinham refutado a veracidade das acusações criminais contra Dilma, era esperado que a presidenta reafirmasse, naquele momento, sua inocência. A partir desse ponto de vista, a princípio, parece natural que Dilma tenha se denominado "vítima de uma grande injustiça”. Contudo, tanto a forma quanto o conteúdo de seu discurso carregam especificidades que não teriam sido escolhidas - ou mesmo imagináveis - em outro contexto histórico-cultural. Para investigar que formas de ser e de fazer política são engendradas pelo discurso de Rousseff, torna-se então necessário compreender a emergência de um novo regime de verdade que reconfigura as noções de sofrimento e de vítima.

Em relação à forma, mais do que um comunicado oficial, o discurso de Dilma assume o formato de um testemunho pessoal. Diante das câmeras, a presidenta divide com o público aspectos reservados à sua intimidade, como emoções - especialmente a tristeza e a indignação - e a narrativa de eventos biográficos. Essas marcas discursivas não são escolhas naturais, mas reflexos de uma sociedade em que o testemunho emerge como um discurso crucial para a produção de subjetividade contemporânea (Vaz et. al., 2014). São essas mesmas marcas discursivas que, como veremos mais adiante, despertarão no outro o sentido de compaixão pelo sofrimento da presidenta.

De acordo com Vaz et. al. (2014), há uma passagem do regime confessional para o do testemunho na pós-modernidade. A confissão foi, desde a Idade Média até a Modernidade, uma das principais tecnologias de produção de subjetividade, em que o sujeito era interpelado a narrar suas culpas e transformar seus desejos em discurso, seja no 
confessionário ou, posteriormente, no consultório do analista (Foucault, 1984). Se antes, por meio da confissão, o indivíduo narrava seus atos e a culpa por tê-los realizado, no testemunho ele deve falar sobre o que sofreu, o que outros fizeram com ele. A emergência dessa nova forma de narrar-se teve entre suas condições de possibilidade a expansão das religiões protestantes, em que a salvação passa a se dar não pela confissão dos atos e pela subsequente absolvição dos pecados, mas pelo testemunho da fé. Na versão secularizada desse discurso, o indivíduo é chamado a testemunhar as dores e marcas de sua história pessoal como instrumento de cura, tanto para si mesmo, quanto para as pessoas que irão ouvi-lo. Nesse sentido, o testemunho se estabelece como um instrumento terapêutico para a expressão pública de uma relação de verdade do indivíduo com ele mesmo.

Assim, o discurso político de Dilma é produzido em meio a uma economia moral em que a exposição pública da dor torna-se uma fonte de valor e de autenticidade. Ao narrar-se dessa forma, Dilma constrói um elo em potencial com seus espectadores em torno do sofrimento, um sentimento que cada vez mais marca as experiências cotidianas em um contexto cultural no qual cada indivíduo é interpelado a entender a si mesmo como um sobrevivente de uma série de traumas (Fassin \& Rechtman, 2009).

Além disso, a forma de narrar a si mesmo passa do âmbito privado - que, na confissão, era representado pelo confessionário ou pelo consultório - para o espaço público, extremamente midiatizado. Os meios de comunicação se configuram como uma arena em que os relatos pessoais emergem e disputam credibilidade e persuasão (Lerner, 2013). As narrativas testemunhais também refletem e promovem uma transformação do lugar do sofrimento, que deixa de ser uma questão exclusiva do foro íntimo. As fronteiras entre público e privado se tornam menos demarcadas e há uma valorização da exposição da intimidade, acompanhada por esses processos de midiatização (Freire Filho, 2014; Sibilia, 2008). Nesse contexto, há um processo de celebrização 9 da política, em que as figuras desse campo passam a ser conhecidas não somente por seus feitos públicos, mas, de forma análoga ao que acontece com as celebridades, sua vida privada e sua personalidade passam

\footnotetext{
${ }^{9}$ A celebrização, para Driessens (2012), consiste na assimilação da lógica da cultura das celebridades em diversos âmbitos sociais que, a priori, não teriam relação com a mídia e a indústria do entretenimento, como a educação, a religião, a medicina e a política.
} 
a ser fonte de interesse e tornam-se fatores fundamentais para o desenvolvimento de sua própria carreira política (Valente, 2012).

Portanto, o discurso de Dilma assume um tom testemunhal. Mesmo levando em conta que o texto foi pensado para ser transmitido e, provavelmente, preparado por uma equipe, o tom biográfico e a expressão de emoções conferem à narrativa maior autenticidade, elevando seu potencial de identificação com o indivíduo comum. No ethos terapêutico que eleva a autoestima como chave de resolução para os problemas da vida cotidiana (Freire Filho, 2012) e para a construção de uma identidade sobrevivente, o discurso de Dilma assume o tom de testemunho de superação, em que o compartilhamento da experiência biográfica de sofrimento se transforma num instrumento terapêutico.

E por que o lugar do sobrevivente assume esse potencial tão grande de produzir identificação? Para destrinchar a raridade discursiva do comunicado de Dilma, faz-se necessário explorar as condições de possibilidade que conferiram à vítima um lugar central no discurso ético-político contemporâneo.

\section{Trauma, sofrimento e política}

A centralidade da figura da vítima e do discurso sobre o sofrimento na produção de subjetividades contemporâneas deriva da popularização e expansão do conceito de trauma. Anteriormente restrito aos impactos físicos, o trauma passa, no final do século XIX, a ser entendido como um problema psíquico, a partir dos estudos de Charcot e, posteriormente, de Freud (Fassin \& Rechtman, 2009; Hacking, 1995). Até os anos 1980, o conceito de trauma raramente era evocado fora do âmbito da psicologia e da psiquiatria. A inclusão da categoria de Transtorno do Estresse Pós-Traumático no Manual Estatístico de Transtornos Mentais (DSM III) naquela década é um sintoma e um promotor da virada no imaginário sobre o trauma psicológico. A categorização dessa doença, que se refere ao reviver compulsivo de um acontecimento traumático por meio de imagens intrusivas e pensamentos, transfere ao evento externo o potencial de causar um trauma. 
As edições seguintes do DSM ampliaram o escopo de eventos possivelmente traumáticos - de experiências extremas como a guerra e os desastres naturais para eventos mais comuns, como ser diagnosticado com uma doença ou ser exposto a alguma forma de violência -, bem como de possíveis vítimas, que passam a ser não só as que experimentam diretamente o acontecimento, mas também as que o testemunharam ou as que convivem com os traumatizados. Para Fassin e Rechtman (2009), o 11 de setembro se configura como um paroxismo desse pensamento ao fundar a ideia de uma nação traumatizada. A categoria de vítima desse acontecimento não se restringe aos que estavam nas Torres Gêmeas, ou aos seus entes queridos, mas passa a abarcar até mesmo as pessoas que se sentiram traumatizadas por assistir ao evento pela televisão.

Essa concepção de trauma se estabeleceu no senso comum como uma verdade partilhada, produzindo um modo contemporâneo de expressar o sofrimento. Um evento traumático não se limita a uma experiência individual, mas pode ser vivida também coletivamente e transmitida, através do partilhar da memória, às gerações seguintes. Assim, diante da multiplicidade de eventos que podem ser entendidos como causadores de trauma, qualquer indivíduo se torna uma vítima em potencial. A possibilidade ou a existência efetiva do trauma passa a interpelar a própria vida cotidiana que, costurada pela linguagem do sofrimento, possibilita a produção de sujeitos que estão em constante processo de luta contra suas feridas psicológicas. Como afirmam Vaz et al (2014).

\begin{abstract}
A presença duradoura do trauma não significa que seus efeitos não possam ser superados; de fato, o trauma é pensado como fundando identidade e um indivíduo pode passar de vítima a sobrevivente, tornando-se alguém que passou por um evento terrível, mas superou, tem uma alta autoestima e ajuda outros a enfrentar seus traumas (Vaz et.al., 2014, p. 23).
\end{abstract}

O sofrimento passa, nesse contexto, por um processo de ressignificação. Ele passa a ser entendido como uma experiência capaz de dar um sentido à narrativa de vida e ganha um potencial político, ao ser capaz de estabelecer laços sociais. $\mathrm{O}$ ato de narrar-se como vítima na contemporaneidade reflete a busca de adesão a uma identidade marcada por uma experiência de violência e dor, que atribui valor a quem a possui - o sobrevivente - e o 
aproxima de todos que na sua vida comum também se veem como vítimas de suas próprias dores.

O lugar de vítima assumido por Dilma em seu discurso expressa aspectos da economia moral da cultura contemporânea. O indivíduo comum que assistiu a seu pronunciamento não é presidente do país e dificilmente experimenta em sua vida algo parecido com um golpe político, mas as verdades disponíveis em sua cultura permitem que ele se veja como um sobrevivente de suas próprias dores inomináveis e experiências intoleráveis. Não analisamos aqui esse comunicado meramente como uma estratégia política de manipulação de eleitores, mas como um discurso que faz sentido no contexto cultural em que foi produzido. Dilma não se coloca apenas como vítima de uma acusação criminal injusta, mas reivindica o lugar de fala de pessoa que sofre. Assim, experiências externas ao contexto do impeachment podem ser incorporadas ao discurso, unidas pelo nexo semântico do sofrimento. Nas palavras da então presidenta:

O destino sempre me reservou muitos desafios, muitos e grandes desafios. Alguns pareciam intransponíveis, mas eu consegui vencê-los. Eu já sofri a dor indizível da tortura; a dor aflitiva da doença; e agora eu sofro mais uma vez a dor igualmente inominável da injustiça. O que mais dói, neste momento, é a injustiça. $\mathrm{O}$ que mais dói é perceber que estou sendo vítima de uma farsa jurídica e política. Mas não esmoreço. Olho para trás e vejo tudo o que fizemos; olho para a frente e vejo tudo o que ainda precisamos e podemos fazer. O mais importante é que posso olhar para mim mesma e ver a face de alguém que, mesmo marcada pelo tempo, tem forças para defender suas ideias e seus direitos..$^{10}$

Nesse contexto, a presença do câncer no discurso merece destaque ${ }^{11}$. Se a doença é associada, em um primeiro momento, a um campo semântico distinto do ambiente político, sua presença no discurso supracitado e o destaque dado a essa menção nos meios de comunicação dialoga com transformações culturais que atribuíram ao câncer uma enorme visibilidade midiática e o potencial de reconfigurar a identidade de seu paciente que,

\footnotetext{
${ }^{10}$ Trecho extraído da declaração dada à imprensa dentro do Palácio do Planalto.

${ }^{11}$ Dilma foi diagnosticada com linfoma em 2009, ano de sua primeira campanha para presidenta, e concluiu o tratamento no mesmo ano.
} 
interpelado por metáforas bélicas que povoam o imaginário em relação à doença, passa a ser enxergado, potencialmente, como um herói (Lerner, 2013; 2015).

Em sua pesquisa acerca dos sentidos produzidos sobre o câncer pela cobertura do jornal $\mathrm{O}$ Globo, Lerner (2015) verificou que as reportagens sobre políticos com essa doença consistiram um dos três eixos temáticos que mais apareceram no corpus pesquisado. Dos 135 textos sobre câncer nas editorias O País e Mundo, mais de 100 abordavam a incidência da doença em figuras da esfera política. Nesses discursos, há uma dimensão moral que estabelece relações entre a forma de gestão da doença e a capacidade do indivíduo de exercer um cargo político. No discurso de Dilma, o câncer foi narrado como um dos desafios que a presidenta teve que enfrentar e dos quais saiu vitoriosa - mas não sem carregar as marcas de sofrimento de uma experiência traumática. A vivência do câncer, ao lado de outras experiências dolorosas, faria da presidenta uma mulher forte e preparada para continuar lutando por seu país.

Além disso, há um endereçamento, na fala de Dilma, de uma sobrevivente do câncer a outros iguais: as tantas mulheres que também sofreram com essa doença - como ela afirma no pronunciamento feito do lado de fora do Palácio -, os familiares dos doentes, e mesmo o indivíduo comum que vive sob o regime do risco, em que a possibilidade de tornar-se doente marca a visão do futuro (Vaz, 1999). O câncer se torna um instrumento de identificação, capaz de criar uma comunidade de sofredores. O testemunho é visto como um caminho terapêutico de expressão das emoções, em que a imagem do sofredor que fala não é de vulnerabilidade, mas de empoderamento. A vítima ocupa um lugar de fala admirado e há uma ressignificação da experiência dolorosa, que passa a ser amplamente mostrada.

Essa dimensão de empoderamento também aparece quando Dilma destaca seu lugar de fala enquanto mulher. Ela ressalta sua posição de primeira presidenta eleita no país, ao mesmo tempo em que se coloca como mais uma mulher brasileira:

Honrei as mulheres desse país, as mulheres que são determinadas, esforçadas, trabalhadoras, que vivem o seu cotidiano desafiando todas as dificuldades. As mulheres mães, as mulheres que são hoje mulheres que querem a sua 
independência, a sua autonomia, o controle de si mesmas. Essas mulheres eu tenho consciência de que eu honrei. Porque as mulheres, nós mulheres, temos uma coisa em comum. Nós somos dignas. Quero dizer a vocês que ao longo da minha vida eu sempre, como todas as mulheres, enfrentei desafios. ${ }^{12}$

O movimento feminista ocupou um papel primordial para a que a vítima passasse a assumir um lugar central na cultura contemporânea. Na busca pela reparação dos crimes de abuso sexual, ele impulsionou as demandas por reconhecimento das vítimas, colaborando para a formação do regime de verdade em que a dor estabelece o terreno para uma causa política (Badinter, 2005; Fassin \& Rechtman, 2009). Ao se narrar discursivamente como uma mulher que enfrentou desafios, representando, assim, todas as mulheres, Dilma assume uma posição de vítima marcada não pela passividade, mas pelo empoderamento.

A menção de Dilma às marcas de gênero presentes em sua experiência de sofrimento dialoga com contexto contemporâneo em que os movimentos feministas se caracterizam fortemente pela prática do compartilhamento de si (Leal, 2016) e em que experiências passadas de sofrimento são publicizadas nas redes sociais e motivam o estabelecimento de comunidades e de causas políticas (Vaz et. al., 2014). A presidenta promove, a partir de seu lugar de vítima, mais uma vez, a identificação com as mulheres brasileiras batalhadoras que enfrentam uma infinidade de desafios em suas vidas cotidianas.

Assim, até mesmo a política em sua noção tradicional - a partidária - não prescinde mais do testemunho como estratégia e ética, já que os sujeitos precisam, cada vez mais, terem sido afetados como indivíduos para se engajarem politicamente. Essa passagem pode ser observada em mobilizações como o \#ficaquerida, organizado pelas administradoras do projeto Eu vejo flores em você $\hat{e}^{13}$. Após a votação da Câmara dos Deputados que autorizou a instauração do processo de impeachment, foram recolhidas mensagens de apoio à presidenta através da página do Facebook do projeto.

\footnotetext{
12 Trecho extraído do discurso de fora do Palácio.

${ }^{13}$ De acordo com a descrição disponível na página oficial, "O projeto Eu vejo flores em você tem como objetivo incentivar a união e o estabelecimento de redes de apoio entre mulheres (...) Nós vamos receber cartas de mulheres para mulheres, ilustrá-las e enviá-las pelo correio sem custo algum. Temos a esperança de que essas cartas afetarão positivamente a auto-estima de muitas de nós, servindo como conforto, força, ânimo, fôlego e inspiração, seja qual for a circunstância".

Disponível

em:

https://www.facebook.com/asfloresemvoce/info/?entry_point=page_nav_about_item\&tab=page_info.

Acesso em: 01 ago. 2016.
} 
Independente de posição política, temos visto Dilma Rousseff ser atacada pela mídia e por machistas de plantão. (...) Nós, do projeto Eu vejo flores em você, decidimos participar da coleta de mensagens de apoio para ela, uma mulher que, como tantas outras, inscreve-se na história de nosso país e, por isso, é atacada ${ }^{14}$ (grifo nosso).

Tanto esse projeto quanto a postura assumida por Dilma em seu discurso mostram que a formação de comunidades de sofrimento dentro do feminismo tem promovido novas formas de mobilização, em que as políticas de identidade e a identificação com a dor presente em trajetórias individuais suplantam as formas tradicionais de fazer política. Como o projeto afirma, se compadecer com o sofrimento da presidenta e ficar ao lado dela enquanto mulher deve ser algo mais importante do que concordar ou não com seu projeto de governo e a ter apoiado nas urnas.

Portanto, quando Dilma reivindica a identidade de mulher sobrevivente, partindo de um discurso que assume, ao mesmo tempo, a forma de um comunicado oficial de uma governante e de um testemunho pessoal de superação, é possível pensar deslocamentos da política tradicional em direção a um entendimento desse campo a partir das micropolíticas, das políticas de identidade e do sofrimento como emoção capaz de estabelecer laços, produzir subjetividades e impulsionar ações individuais e coletivas. Buscaremos, a seguir, analisar o estabelecimento desses laços em torno da ideia de compaixão.

\section{Os sentidos da compaixão pós-moderna a partir do sofrimento de Dilma Rousseff}

À noção de vítima discutida aqui estão atreladas as concepções de dor e sofrimento ${ }^{15}$, e é o reconhecimento desta dor/sofrimento no outro que leva o eu à compaixão, uma das quatro emoções socializantes - junto à vergonha, a culpa e ao asco (Vaz, 2014). De origem latina, a palavra compaixão (compassio) traz em sua etimologia a ideia de sofrer com, sentir o que o outro sente. Desta forma, analisaremos esta emoção em sua concepção pós-moderna no

15 Para os teólogos, a dor e o sofrimento referem-se, respectivamente, a questões do corpo e da alma; distinção que não utilizaremos neste material. 
contexto do afastamento da presidenta Dilma Rousseff, que em seu último pronunciamento na parte externa do Palácio do Planalto afirmou ter sua tristeza diminuída e um momento de alegria "com o calor, a energia e o carinho" compartilhados pelos que ali estavam para apoiá-la.

Segundo Vaz (2014), o conceito de compaixão, afetado por questões histórico-culturais de épocas distintas, passou por uma série de transformações até chegar ao seu entendimento contemporâneo. Tais mudanças evidenciam-se tanto na forma como cada sociedade define “(...) quem pode ser objeto de compaixão, quem deve ajudar e quem, ou o que, é tido como responsável pela existência de sofrimentos" (Vaz, 2014, p. 74), quanto nas crenças que orientam os indivíduos a experimentarem tal emoção por um outro sofredor.

Enquanto não se deu, na história da humanidade, uma universalização da regra moral, as sociedades eram regidas por laços comunitários que determinavam o pertencimento ou não pertencimento a grupos específicos. Boltanski (1999) explica que havia uma separação entre nós e eles que indicava quem merecia solidariedade ou indiferença diante de uma situação de sofrimento. Essa concepção fazia ainda com que a solidariedade com o sofredor não fosse obrigação de todos os indivíduos e que o sofrimento do outro, fora dessas comunidades, fosse visto como decorrência de uma condição moral inferior. Tal noção foi afetada com a chegada do Cristianismo na cultura Ocidental, que, a partir da obrigação de solidariedade com estranhos, propôs uma ampliação das possibilidades de quem deveria ser visto como sofredor. Entretanto, essa compaixão cristã operava fora da política, ela conduzia a uma ação local, imediata.

Durante o período da Revolução Francesa, o sofrimento do outro passa a ser capaz de motivar a ação política de todo aquele que não era sofredor. As aflições alheias passam a ser vistas como condições diretamente vinculadas a características da sociedade que deveriam ser transformadas em prol de um projeto político de igualdade. Nessa concepção moderna, emerge um modo específico de se narrar o sofrimento (Vaz, 2014), com suas possibilidades retóricas orientadas pela maneira como se comportam quatro figuras: $o$ sofredor (que é representado); o observador (que representa); o responsável pelo sofrimento (que ajuda ou que causa); e a audiência (que recebe a representação e pode fazer algo pelo sofredor a partir da ação política). Veremos que tais figuras, na 
contemporaneidade, se refazem constantemente em torno da emergência de cada vez mais modernas tecnologias de informação e comunicação (TICs).

Vaz (2014, p. 77) explica que, ainda no contexto moderno, “o sofrimento é observado por quem não sofre e narrado para outros que também não sofrem”. Cabe aqui ao representante se implicar no enunciado, indignando-se diante daquele que causa a dor ou compadecendose perante aquele que ajuda o sofredor. Já à audiência, além do compadecimento ou indignação, cabe a ação política capaz de reduzir a dor do sofredor; ela "deve também, portanto, mobilizar, redigir petições, manifestar nas ruas, organizar greves e paralisações, votar por quem defende a causa do sofredor, ou mesmo lutar abertamente contra as forças da ordem" (Vaz, 2014, p. 77), assumindo, pois, um lugar de responsabilidade neste cenário. No contexto desta narrativa específica, o sofredor aparece como despersonalizado e sua dor só importa na medida em que representa uma condição comum a muitos outros sujeitos. Logo, o sofredor também é um representante; neste caso, um representante de outros indivíduos que padecem de agruras semelhantes e condicionadas pelos mesmos fatores.

Com as transformações contemporâneas na concepção de compaixão, emerge também a ideia de ilegitimidade da representação do sofredor. O testemunho dado pela vítima do sofrimento carrega consigo o peso do discurso narrado, sem mediações de terceiros, por quem de fato vivenciou determinada situação penosa e, logo, possui a autoridade da experiência. A chegada das TICs acabou por aproximar o sofredor e a audiência sem que houvesse a necessidade de um representante entre eles; os relatos autobiográficos na forma testemunhal passaram a ser comumente encontrados.

Aproximando tais conceitos ao lugar de vítima em que se coloca Dilma Rousseff, bem como ao contexto atual de narrativas de sofrimento, temos na figura da própria presidenta o lugar do sofredor que, não necessitando mais de um representante e possuindo a autoridade da experiência vivida, fala diretamente à audiência mediante o seu discurso/testemunho amplamente midiatizado. Ao falar das diferentes dores que já a acometeram e hoje a acometem, Dilma se apresenta como uma sofredora, que alcança a identificação do outro pelo simples fato de compartilhar de agruras semelhantes. A audiência mantém a responsabilidade da ação política no sentido de buscar amenizar, ou mesmo acabar, com as dores que acometem o sofredor. 
Por se tratar de um discurso inserido no cenário de um processo de impeachment, é esperado que a presidenta tenha se concentrado em reafirmar a dor que sente pela injustiça da "farsa jurídica e política" que a cerca. Neste sentido, Dilma aponta os responsáveis por causar a "dor inominável da injustiça", além de fazer alusão aos que se compadecem de sua situação e, logo, a auxiliam na superação deste sofrimento. A presidenta afirma ser a "oposição inconformada" o responsável direto pelo "golpe" e, consequentemente, pela dor que está sentindo ao ser julgada; posteriormente, ela estende ao povo brasileiro consequências possíveis dos atos da dita "oposição inconformada":

[...] o golpe não visa apenas me destituir, destituir uma presidenta eleita pelo voto de milhões de brasileiros, voto direto em uma eleição justa. Ao destituir o meu governo querem, na verdade, impedir a execução do programa que foi escolhido pelos votos majoritários dos 54 milhões de brasileiros e brasileiras. $\mathrm{O}$ golpe ameaça levar de roldão não só a democracia, mas também as conquistas que a população alcançou nas últimas décadas ${ }^{16}$.

Esta extensão ao povo brasileiro faz com que os não sofredores se identifiquem e temam pela possibilidade de serem acometidos por sofrimento semelhante. Amparados em um pensamento contemporâneo, como veremos mais adiante, acreditamos que este processo de identificação, em suas diversas facetas, pode levar o observador/não sofredor a ações políticas com o intuito de reverter o curso do processo. Ao voltar-se para o povo na rampa do Palácio do Planalto, Dilma Rousseff declarou: "hoje para mim é um dia muito triste. Mas vocês, vocês conseguem fazer com que a tristeza diminua e que eu tenha aqui junto com vocês, com o calor, a energia e o carinho que vocês passam para mim, eu tenha aqui um momento de alegria". Neste fragmento de discurso a presidenta faz alusão à ideia de compaixão no sentido de que uma dor, ao ser compartilhada - sentir com o outro -, pode ser amenizada.

Por ser uma emoção, a compaixão está diretamente ligada às crenças de quem a vivencia; tais crenças, por sua vez, relacionam-se com a cultura em que o sujeito experienciador se insere. No sistema de crenças da Modernidade, o observador tinha o poder de decidir sobre

\footnotetext{
16 Trecho extraído da declaração dada à imprensa dentro do Palácio do Planalto.
} 
a gravidade do sofrimento do outro, sendo a compaixão orientada pela moralidade enquanto os inocentes seriam merecedores dela, os imorais seriam responsáveis por seu próprio sofrimento. Havia, além disso, a prerrogativa da existência de uma distância entre o observador e o sofredor. Assim, era do observador o poder de decidir quem seria digno de compaixão.

Na passagem da Modernidade para a Pós-modernidade, deram-se mudanças nos juízos morais que orientam a existência da compaixão. A prerrogativa dada ao observador para reconhecer ou negar a gravidade do sofrimento de um indivíduo passa a ser questionada. Emerge o argumento de que o observador que não se compadece pode estar menosprezando a dor do outro por não o considerar um igual. Com o passar do tempo a apreensão do sofrimento também foi transformada, e se antes a autoridade do observador requeria que a dor estivesse expressa no corpo do sofredor, com a Pós-modernidade, formas intencionais de exposição do sofrimento também são tidas como válidas, a exemplo da linguagem e dos movimentos de face. Dá-se, pois, a passagem do corpo do sofredor à consciência do seu sofrimento, o que implica, para Vaz (2014, p. 86), “dar maior peso ao próprio sofredor na determinação da gravidade de sua dor" que não será mais mediada por um observador/representante. Uma consequência disso seria a ampliação das possibilidades do que pode ser considerado sofrimento no espaço público e, logo, merece solidariedade.

Uma vez que não cabe mais ao observador o julgamento acerca da gravidade do sofrimento do outro, e que o sofredor agora tem voz de autoridade quando se afirma enquanto vítima, podemos reconhecer - no sentido de ratificar - o lugar em que se coloca a presidenta Dilma Rousseff ao tratar do impeachment como golpe que a aflige. Não só a narrativa do sofrimento vivenciado no contexto do seu afastamento da Presidência da República, mas também as narrativas das dores da tortura e do câncer chegam à audiência, através das TICs, carregadas de uma autoridade inerente ao lugar de fala de quem viveu e/ou está vivendo essas dores. Neste sentido, temos tanto os que acreditam no testemunho da presidenta Dilma e se compadecem com seu sofrimento; quanto aqueles que, por não se enxergarem como iguais ou condenarem moralmente suas ações ou seu projeto político, menosprezam a sua dor. 
Já no que se refere à distância entre observador e sofredor, temos que na Modernidade ela pressupunha a demarcação entre felizes (quem não sofre e observa) e infelizes (quem sofre e é observado). Somava-se a essa demarcação a diferença entre segurança e insegurança, que diz respeito ao risco/possibilidade de vivenciar o sofrimento. Na Pós-modernidade, o indivíduo feliz passou a saber do sofrimento do outro mais fácil e rapidamente, por mediação técnica, diretamente do sofá da sua casa.

Diante do apelo de um sofredor, o indivíduo privado tornado cidadão imaginava como seria viver numa dada condição produzida pela estrutura social. Imaginava, mas à distância, sabendo que dificilmente o imaginado se transformaria em realidade. A compaixão pós-moderna, por sua vez, visa reduzir ao máximo a distância entre sofredor e audiência (Vaz, 2014, p. 90-91).

Neste sentido, dois procedimentos visam aproximar o observador do sofredor. O primeiro deles trata-se do privilégio concedido a determinados tipos de sofrimento, como os que evidenciam o fato de que uma rotina feliz de um sujeito inocente pode ser subitamente interrompida. Já o segundo é um procedimento retórico, visando garantir a identificação da audiência uma vez que esta acredite que algo semelhante está no seu horizonte de possibilidades.

Sobre o primeiro procedimento Vaz (2014, p. 91) defende que o amplo espaço concedido pelos meios de comunicação para acidentes, atentados terroristas, catástrofes naturais e crimes entre estranhos ocorridos no espaço público "não se deve apenas ao fato de que tais eventos permitem a produção de imagens espetaculares; também se deve ao novo lugar de referência para juízos críticos em nossa cultura: a felicidade do indivíduo qualquer". Acerca do procedimento retórico, temos que, se, de um lado, todo feliz pode subitamente tornar-se um infeliz, de outro, é comum depararmos com o discurso midiático de que todo sofredor era feliz, independentemente de sua condição social; esta felicidade como virtude é essencialmente igualitária.

Assim sendo, com a sensação de diluição de distâncias entre os sofredores e os não sofredores possibilitada pelo uso das TICs, cada vez mais a audiência recebe, sem a mediação de um representante, o testemunho autobiográfico daquele que sofre, 
interpretando-o no sentido de imaginar-se vivenciando aquela mesma dor, ou dor semelhante. No caso aqui abordado, a possibilidade de pessoas comuns vivenciarem a mesma situação experimentada por Dilma Rousseff no contexto do impeachment é mínima. Todavia, essas pessoas se compadecem diante da dor da injustiça, que, a partir de processos de identificação, atravessa o cotidiano de todos que se enxergam como vítimas em seus próprios sofrimentos.

\section{Considerações finais}

A análise do discurso de afastamento de Dilma Rousseff revelou que a presidenta se dirigiu ao público na forma de um testemunho pessoal, assumindo um lugar de vítima que transcende o contexto do impeachment. O "golpe político" é classificado em sua fala como uma experiência de sofrimento a ser superada, assim como outros eventos dolorosos de sua trajetória de vida: a tortura militar e o câncer. A presidenta se apresenta como mais um indivíduo em luta contra as dores da vida e é o seu posicionamento neste lugar de fala que, potencialmente, suscita a compaixão do indivíduo comum. O testemunho de Dilma atua como instrumento terapêutico para compartilhar a dor com uma comunidade unida em torno da vivência do sofrimento, uma experiência que, como vimos, é capaz de estabelecer laços e identidades partilhadas no contemporâneo.

Ao longo desta reflexão, nos perguntamos: por que este discurso e não outros que seriam ou já foram possíveis? Em outros tempos, poderíamos pensar que um governante se colocaria diante do público como um ser extraordinário, que deveria ser seguido por possuir algo diferente das pessoas comuns - uma centelha divina, o sangue real, o chamado do herói. Talvez, em outra economia moral, a emoção que predominasse em seu discurso fosse a raiva contra os inimigos, clamando a vingança como ação política necessária contra um "golpe injusto". As marcas discursivas do comunicado também poderiam ser outras: uma defesa formal, apoiada na exposição impessoal dos fatos, era um caminho válido a ser seguido por um chefe de estado no exercício de seu cargo. 
Sendo assim, reforçamos o nosso argumento de que o formato testemunhal e o conteúdo emocional do discurso de Dilma só foram possíveis por estarem inseridos em um contexto contemporâneo em que o sofrimento emerge como experiência que dá sentido às narrativas de vida de indivíduos que passam a se enxergar como vítimas constantes de uma série de eventos traumáticos. A política tradicional no regime democrático, exercida no governo da nação, não se restringe ao exercício do voto e na representação partidária, mas abarca novas formas de entendimento da ação política e da construção de subjetividades no contemporâneo.

Dessa forma, o testemunho atua como um conector entre a vida íntima do sujeito - repleta de seus sofrimentos e das memórias de suas experiências - e um espaço público formatado, cada vez mais, em torno de políticas de identidade. A compaixão emerge, pois, como uma das principais emoções que move essas formas contemporâneas de fazer política ao interpelar os cidadãos a compartilhar do sofrimento exposto através dos meios de comunicação e, a partir daí, buscar formas de ação para amenizar ou evitar essa dor do outro, que é também a sua dor. Isso ocorre na medida em que, mesmo com diferentes eventos causadores, pessoas de diversas realidades passam a enxergar entre elas, a partir das verdades de seu tempo, um nexo comum: a experiência cotidiana (e, nem por isso, menos traumática) do sofrimento e a necessidade urgente da superação para tornar-se um sobrevivente em sua trajetória de vida. Portanto, o estudo de caso empreendido aqui ilustra como o sofrimento e a compaixão ocupam um papel central no engendramento de formas de ser e de perceber as relações sociais, perpassando as formas de fazer política na contemporaneidade.

\section{Referências}

BADINTER, Elisabeth. Rumo equivocado: o feminismo e alguns destinos. Rio de Janeiro: Record, 2005.

BOLTANSKI, Luc. Distant suffering: morality, media and politics. Cambridge: Cambridge University Press, 1999.

DRIESSENS, Oliver. The Celebrization of society and culture. International Journal of Cultural Studies, [S.I], v.16, n. 6, p. 641-657, set., 2012. 
FASSIN, Didier; RECHTMAN, Richard. The empire of trauma. Princeton, Oxford: Princeton University Press, 2009.

FOUCAULT, Michel. A Arqueologia do saber. Rio de Janeiro: Forense Universitária, 2009. A ordem do discurso. São Paulo: Loyola, 2011

História da sexualidade - Volume 1: A vontade de saber. Rio de Janeiro: Graal, 1984.

FREIRE FILHO, João. A "neurose da exibição" na Era do Reclame. In: FRANÇA, Vera; FREIRE FILHO, João; LANA, Lígia; SIMÕES, Paula. Celebridades no século XXI: transformações no estatuto da fama. Porto Alegre: Sulina, p. 37-70, 2014,.

"Autoestima é tudo!": anotações para um Dicionário de ideias feitas sobre a felicidade. In: FREIRE FILHO, João; RIBEIRO, Ana Paula Goulart e HERSCHMANN, Micael (orgs.). Entretenimento, felicidade e memória: forças moventes do contemporâneo. Rio de Janeiro: Anadarco, p. 35-63, 2012.

HACKING, lan. Rewriting the soul: multiple personality and the sciences of memory. Princeton, New Jersey: Princeton University Press, 1995.

LEAL, Tatiane. "Chega de fiu fiu": feminismo, emoções e mobilização política por meio de práticas de compartilhamento de si. In: JESUS, Eduardo; TRINDADE, Eneus; JANOTTI Jr., Jeder; ROXO, Marco (Orgs.). Reinvenção comunicacional da política: modos de habitar e desabitar o século XXI. Salvador: Edufba; Brasília: Compós, p. 97-112, 2016.

LERNER, Katia. Doença, Jornalismo e Visibilidade: Notas sobre a Cobertura do Câncer no Jornal O Globo. In: XXXVIII Congresso Brasileiro de Ciências da Comunicação, Rio de Janeiro, 2015. Anais do XXXVIII Congresso Brasileiro de Ciências da Comunicação, 2015.

Doença, Mídia e Subjetividade: Algumas Aproximações Teóricas. In: Anais do XXXVI Congresso Brasileiro de Ciências da Comunicação, Manaus, 2013.

SIBILIA, Paula. O show do eu: a intimidade como espetáculo. Rio de Janeiro: Nova Fronteira, 2008.

VALENTE, Filipe Martins. Celebridade Política: análise da imagem e do discurso de Pedro Passos Coelho e de José Sócrates nas legislativas de 2011. Dissertação de Mestrado (Jornalismo). Universidade da Beira Interior, Corvilhã, 2012.

VAZ, Paulo. Corpo e Risco. Forum Media, Viseu, v. 1, n.1, p. 101-111, 1999.

; Compaixão, Moderna e atual. In: João Freire Filho; Maria das Graças Pinto Coelho. (Org.). Jornalismo, cultura e Sociedade: visões do Brasil Contemporâneo. 1ed. Porto Alegre: Sulina, v. 1, p. 73-96, 2014.

; RONY, Gaelle. Políticas do sofrimento e as narrativas midiáticas de catástrofes naturais. Famecos, Porto Alegre, v. 18, n. 1, p. 212-234, janeiro/abril 2011.

Paulo; SANTOS, Amanda; ANDRADE, Pedro Henrique. Testemunho e subjetividade contemporânea: narrativas de vítimas de estupro e a construção social da inocência. Lumina, v. 8, n. 2, p. 1-33, dez.,2014. 


\section{As autoras}

Amanda Medeiros é doutoranda em Comunicação e Cultura pela ECO-UFRJ e mestre em Estudos da Mídia pela UFRN. Bolsista Capes. amanda.cnth@gmail.com

Tatiane Leal é doutoranda e mestre em Comunicação e Cultura pela ECO-UFRJ. Bolsista CNPq. tatianeclc@gmail.com 